\title{
On Methods to Legal Regulation of Artificial Intelligence in the World
}

\author{
Zarina I. Khisamova, Ildar R. Begishev, Ramil R. Gaifutdinov
}

\begin{abstract}
In the modern digital age, the issues of using artificial intelligence and the field of development of intelligent technologies are extremely important and relevant. Over the past few years, there have been attempts of state regulation of artificial intelligence, both in Russia and in other countries of the world. Artificial intelligence poses new challenges to various areas of law: from patent to criminal law, from privacy to antitrust law. Among the current approaches, the most optimal is the creation of a separate legal regulation mechanism that creates a clear distinction between areas of responsibility of developers and users of systems with artificial intelligence and the technology itself. Today, the development of the legal framework for the existence of artificial intelligence can be conditionally divided into two approaches: the creation of a legal framework for the introduction of applied systems with artificial intelligence and stimulate their development; regulation of the sphere of creating artificial "super intelligence", in particular, compliance of the developed technologies with generally recognized standards in the field of ethics and law.
\end{abstract}

A separate area should be the introduction of uniform ethical principles for all developers and users of systems with artificial intelligence. The most optimal in this aspect is the approach implemented within the framework of the Asilomar principles. In these circumstances, the appeal to the problem of legal regulation of artificial intelligence is becoming more relevant than ever. This paper presents the results of a detailed analysis of existing approaches to the legal regulation of artificial intelligence.

Key words: artificial intelligence; robot; intellectual technologies; digital economy; machine learning; technological singularity; superintelligence; legal regulation; information law; law; legislation; Asilomar principles.

\section{INTRODUCTION}

Humanity is on the verge of an era when expanding of the artificial intelligence application horizons unleashes a new digital revolution. The use of artificial intelligence inevitably leads to the problem of ethical choice, raises legal issues that require operative intervention. The paper analyses the main global approaches to the legal regulation of artificial intelligence.

\section{MATERIALS AND METHODS}

The materials for the work were the provisions of foreign legislation on the legal regulation of artificial intelligence, as well as various statistics in this area.

Revised Manuscript Received on November 09, 2019.

* Correspondence Author

Zarina I. Khisamova - Ph.D. in Law, Head, Department of Planning and Coordination of Research Activities, Research Department, Krasnodar University of the Ministry of Internal Affairs of the Russian Federation

Ildar R. Begishev - Ph.D. in Law, Honored Lawyer of the Republic of Tatarstan, Senior Researcher, Kazan Innovative University named after VG Timiryasov (IEML)

Ramil R. Gaifutdinov - Ph.D. in Law, Kazan Federal University, Faculty of Law, Criminal law Department
The reliability of the results obtained is provided on the basis of analysis of a significant and necessary array of legislative norms, statistical data, as well as the use of modern methods of researching legal institutions: historical and legal, logical, formal-legal, comparative law, systemic-structural and other methods of scientific knowledge.

\section{RESULTS AND DISCUSSION}

Nikola Tesla predicted that in the 21 st century "automatic machines (robots) will take on all the monotonous work, and take the place that slave labour occupied in ancient civilization, and then humanity will be freed to realize its highest aspirations. "For modern man, robots and artificial intelligence have become an element of objective reality, and since the mid-20th century, interest in artificial intelligence as a subject of scientific discussion around the world continues to grow, especially in Europe, the USA and China [1].

Analysts around the world unanimously call artificial intelligence a key technology trend. According to analysts, by 2020 , the artificial intelligence market will grow to $\$ 5$ billion [2] through the use of machine learning and natural language recognition technologies in advertising, retail, finance and healthcare.

The expert and scientific community predicts that with the rapid growth of investments in artificial intelligence and the expansion of the scope of their application, a new problem would be at the forefront: a legal regulation which is inextricably linked with ethical aspects. "Postulates of Azimov about non-harming to humans and humanity by smart robots do not cause emotions in most experts long ago". [3] A period of 60 years, determined by scientists and futurologists to achieve technological singularity, is just around the corner [4]. According to R. Kurzweil, when this happens, computers will be able to grow exponentially in comparison with themselves and reproduce themselves, and their intelligence will be billions of times faster than human [5].

According to Moore's law, the thinking processes of robots can no longer be distinguished from human ones, the similarity will reach $95 \%$ [6]. If this happens, humanity will face unprecedented legal challenges. Modern legal systems that exist on the basis of anthropocentrism inherent to humanity since the Renaissance era do not let it today to solve arising problems with the development of technology [7, 8]. As R. Ibragimov and E. Suragina correctly note, all the principles concerning regulation of program creation processes (including robots) are somehow subordinated to two global goals:

"1) to ensure the protection of man, his rights and fundamental freedoms, as well as the protection of society, the state and humanity; 
2) to contribute to the development of technological progress in the field of the latest information technologies and robotics to the extent that this does not contradict the achievement of the first goal"[9].

With regard to artificial intelligence, it should be noted that the request for legal regulation is due both to the presence of sectoral legal problems in the current legal field that impedes the development of technologies, and the desire to intensify the process of implementation of technologies within the digital economy, which necessitates the creation of appropriate regulatory mechanisms [10].

Today, the development of the legal basis for the existence of artificial intelligence can be divided into two approaches:

- Creation of a legal basis for the implementation of applied systems with artificial intelligence and stimulate their development;

Regulation of the sphere of creating artificial "superintelligence", in particular, the compliance of the developed technologies with generally recognized standards in the field of ethics and law.

In fairness, it is worth noting that the current level of artificial intelligence machine system development does not pose an acute problem of "deterring" artificial intelligence as a potential threat to humanity. At the same time, the existence of existential risks of such a rapid artificial intelligence development is quite obvious. Artificial "superintelligence" may appear quite soon. In these conditions, the adoption of the Asilomar principles of artificial intelligence in January 2017 at the conference in Asilomar, USA (2017 Asilomar conference) was the first and very significant step of the responsible approach of mankind to the development of artificial intelligence and robotics.

Among the key positions of this document there should be noted:

- the principle of "useful" financing, which implies an infusion of investments in research to ensure the useful use of artificial intelligence in search of an answer to the most acute problems;

- the principle of "the connection between science and politics", which provides for constructive and useful interaction between researchers in the field of artificial intelligence and those who make decisions on the regulation of artificial intelligence;

- the principle of "security" and "transparency of failures", as well as the programming of artificial intelligence based on universal principles of morality.

A separate direction highlighted the risks that entail the creation of artificial intelligence and measures to limit them: So, developers of artificial intelligence systems play a key role in shaping the moral consequences of using artificial intelligence, the misuse of artificial intelligence and the actions of artificial intelligence; they have the ability and responsibility to influence such consequences. At the same time, the Principles proclaim an anthropocentric approach: "people must choose for themselves how to use artificial intelligence systems to achieve their goals, and whether to use them for this at all".

Special attention is also paid to the confidentiality of personal data and to ensuring the basic rights of humanity and society. In the long run, the principle of developing "superintelligence" was proclaimed only under vigilant supervision, only to serve widely shared ethical ideals and for the benefit of all mankind, as well as the need to minimize the possible risks of systems with artificial intelligence even at the forecasting stage.

It is noteworthy that the Principles were signed not only by scientists concerned with ethics and moral issues, for example, S. Hawking and R. Kurzweil, but also IT experts, as well as major IT entrepreneurs, such as I. Mask and B. Gates. A. Neznamov proposes to divide the approaches in legal regulation into 4 levels depending on the scope of regulation:

1) Private initiative and research institutes;

2) Self-regulation in the industry;

3) National regulation;

4) Supranational regulation [3].

With positive assessment of this initiative, we note that, in our opinion, it is advisable to distinguish 3 levels by combining private (expert) initiative and self-regulation.

The expert community, consisting of IT specialists, scientists, lawyers, economists and entrepreneurs, is the driving force that ensures self-regulation of the industry. A vivid example of this is the Asilomar principles which were signed by 3,500 specialists. The group also includes initiatives to create ethical principles for the developed artificial intelligence. Microsoft has released a report on the impact of artificial intelligence on humanity, which has proposed including the introduction of an analogue of the "Hippocratic Oath" for programmers [11]. The Ethics Advisory Group of the European Data Protection Inspector published a report predicting a shift from individual to distributed responsibility, pointing out inadequate regulation and the need for digital ethics [12,18].

National regulation as an independent level of legal regulation has not yet been fully formed. In individual countries, private initiatives are being implemented.

In South Korea, in 2008, the Law on Promoting the Development and Distribution of Smart Robots was passed. The content and essence of this document does not allow it to be recognized as an act regulating social relations in this area. The document aims to stimulate the development of "smart" robotics. However, the law contains a number of significant concepts and definitions. So, it is determined that a "smart robot" is "a mechanical device that independently perceives the external environment; it recognizes the circumstances in which it works, and it moves independently." At the same time, the law declares the ability of the state to adopt a special legislation regulating the ethical standards for the development of robotics, which developers, manufacturers and users of smart robots must follow [13,17].

Note that South Korean law was the first initiative to develop a strategy for artificial intelligence. If in 2017 five countries adopted the National Strategy for Artificial Intelligence, then during 2018-2019 there were already 30 of them. So, in the UAE, China, France, Sweden, Mexico, Singapore, Japan and Germany, Strategies in the field of artificial intelligence have been developed. "In other countries, they set themselves the task of becoming leaders, to be among the leaders in technology development, or to become leaders in some of the areas in the field of artificial intelligence."

Special attention should be paid to the Chinese "Plan for the Development of Artificial Intelligence Technologies of the New Generation until 2030" (July 2017), according to which the country should become the world leader in the field of artificial intelligence, and the associated areas of the economy 
should bring at least $\$ 150$ billion US income. Within the framework of the plan, a number of state and private-state programs have been developed aimed at ensuring the competitiveness of China in the field of artificial intelligence $[14,15]$. Over the past few years, China has made a breakthrough in the development of artificial intelligence technologies and has become the second country in this area after the United States.

However, we note that China, unlike the United States and Great Britain, is focused on the economic benefits of introducing artificial intelligence. Issues of ethical and legal support for the development of artificial intelligence are in their infancy. Attention is paid only to the policy of ensuring control of Chinese companies over valuable data, including by storing data on Chinese users in the country, the mandatory use of national standards of the PRC in areas related to artificial intelligence, including cloud computing, industrial software and big data $[14,16]$.

In the United States, the issue of reviewing progress in the field of artificial intelligence technologies is a national priority. The founding document is the National Strategic Research and Development Plan for Artificial Intelligence, which contains a strategic research and development plan funded by the federal government in the field of artificial intelligence. In March 2018, a provisional National Security Commission on Artificial Intelligence was established in the country, and an interdepartmental structure was created to review progress in the field of artificial intelligence technologies. It should be noted that among government tasks, priority is given to fundamental research in the field of artificial intelligence with a focus on research initiatives in which private business does not plan to invest, that is, areas that are not commercially attractive.

The United States is also actively collaborating with the United Kingdom in the application of artificial intelligence for military purposes, in particular, in establishing a balance between the legitimate and unlawful use of technologies that affect national security.

The UK is rightfully considered the world leader in the field of ethical standards for robotics and artificial intelligence systems. The state supports the application and development of artificial intelligence in business in accordance with the "Digital Economy Strategy 2015-2018" approved at the beginning of 2015 by the state organization Innovate UK (Introduce Innovations in the UK), and the UK Digital Strategy.

\section{SUMMARY}

The basis of the legal regulation of artificial intelligence should be the differentiation of levels of legal responsibility between developers and users of artificial intelligence.

A separate area of the legal regulation of artificial intelligence should be the introduction of moral and ethical principles common to all developers and users of artificial intelligence.

\section{CONCLUSION}

Summing up the analysis, we note that speaking about the normative legal regulation in the field of artificial intelligence, it should be understood how the current legislation takes into account the possibility of the existence of such systems and can be applied to organize relationships in the conditions of their use ${ }^{1}$.

Artificial intelligence creates new challenges to various areas of law: from patent to criminal law, from the protection of private life to antitrust law. Among the approaches that currently exist the most optimal is the creation of a separate legal regulation mechanism that creates a clear distinction between areas of responsibility between developers and users of systems with artificial intelligence and the technology itself. A separate area should be the introduction of uniform ethical principles for all developers and users for systems with artificial intelligence. The most optimal in this aspect is the approach implemented within the framework of the Asilomar principles. We believe that these Principles can become the basis for supranational mechanisms of legal regulation in the sphere of development and implementation of artificial intelligence.

\section{ACKNOWLEDGEMENTS}

The work is performed according to the Russian Government Program of Competitive Growth of Kazan Federal University. The authors are sincerely grateful to the head of the Department of Criminal Law of the Faculty of Law of the Kazan Federal University for help in the preparation of this paper.

\section{REFERENCES}

1. Shoham Y., Perrault R., Brynjolfsson E., Clark J., Manyika J., Niebles J.C., Lyons T., Etchemendy J., Grosz B., Bauer Z. The AI Index 2018. Annual Report. AI Index Steering Committee. Human-Centred AI Initiative, Stanford University, Stanford, CA, December 2018.

2. Kuznetsova N. Investments in artificial intelligence are breaking records / N. Kuznetsova // Invest-Foresight. Business magazine. - May 29, 2018. - URL: https://www. if 24 ru/investitsii-v-iskusstvennyj-intellekt-byut-rekordy/

3. Neznamov A. Laws of robotics. How to regulate artificial intelligence / A. Neznamov // Forbes. - URL: https://www. forbes. ru/tehnologii/355757-zakony-robototehniki-kak-regulirovat-iskusstve nnyy-intellekt

4. Bostrom N. Superintelligence: Paths, Dangers, Strategies / N. Bostrom - Oxford : Oxford University Press, 2014. - 390 p.

5. Kurzweil R. The singularity is near: when humans transcend biology / R. Kurzweil. - Duckworth, 2010. - 1012 p.

6. Bostrom N. Strategic Implications of Openness in AI Development / N Bostrom. - Future of Humanity Institute, University of Oxford, 2017. 14 p. - URL: https://nickbostrom.com/papers/openness.pdf

7. Pagallo U. The Laws of Robots: Crimes, Contracts, and Torts / U. Pagallo. - Dordrecht : Springer, 2013. - 200 p.

8. Leach R. Political ideology in Britain / R. Leach. - 2nd ed. - London Palgrave Macmillan, 2009. - $282 \mathrm{p}$.

9. Ibragimov R. Law of machines. How to hold a robot accountable ?/ R. Ibragimov, E. Suragina // Corporate Lawyer. - 2017. - No. 11. - P 10-17.

10. Yoav Shoham, Raymond Perrault, Erik Brynjolfsson, Jack Clark, James Manyika, Juan Carlos Niebles, Terah Lyons, John Etchemendy, Barbara Grosz and Zoe Bauer, «The AI Index 2018 Annual Report», AI Index Steering Committee, Human-Centered AI Initiative, Stanford University, Stanford, CA, December 2018.

11. Smith B., Shum H. The Future Computed: Artificial Intelligence and its role in society, Microsoft, 2018. - URL https://blogs.microsoft.com/uploads/2018/02/The-Future-Computed_ 2.8.18.pdf

12. Burgess J. P. et al., Ethics Advisory Group Report 2018. - URL https://edps.europa.eu/sites/edp/files/publication/18-01-25_eag_repor t_en.pdf

13. Simachev Y., Sokolov A. New Principles and individual practices in legal regulation amid
technological revolutions. Report 
of Centre of Development Institute, the Institute for Statistical Studies and Economics of Knowledge, the Skolkovo HSE Institute for Law and Development, Institute of Legal Regulation, the Institute for Transport Economics and Transport Policy Studies and the Institute of Education of National Research University Higher School of Economics. (2018). International forum "Development of parliamentarism". - $18 \mathrm{p}$.

14. Komissina I. I. The current state and prospects for the development of artificial intelligence technologies in China / I. I. Komissina // Problems of the national strategy. - 2019. - No. 1. - P. 137-159.

15. Rezaei, M., \& Nemati, K. The Impact of Purchase Intent, Word of Mouth Advertising and Skill Domain of Seller on Quality of Customer Relationship to Sale Life and Savings Insurance Policies (Case Study: Dana Insurance Co., Bushehr Province). Dutch Journal of Finance and Management, 1(2), (2017). 43. https://doi.org/10.29333/djfm/5819

16. Fujo, M. H., \& Dida, M. A. Centralized Admission System for Advanced Level Private Schools: Case of Kilimanjaro Region, Tanzania. Journal of Information Systems Engineering \& Management, 4(1). (2019).

17. Saidi, S. S., \& Siew, N. M. Assessing Students' Understanding of the Measures of Central Tendency and Attitude towards Statistics in Rural Secondary Schools. International Electronic Journal of Mathematics Education, 14(1), (2019). 73-86. https://doi.org/10.12973/iejme/3968

18. Baykalova, E. D., Artyna, M. K., Dorzhu, N. S., Ochur, T. K., \& Mongush, D. S. Morphological interference in the process of mastering English speech in conditions of interaction of Tuvan, Russian and English as a foreign language. Opción, 34(85-2), (2018). 35-60. 